\title{
Food classification system based on food processing and its relationship with nutritional status of adults in Terengganu, Malaysia
}

\author{
${ }^{1 *}$ Asma', A., ${ }^{1}$ Gan, H.J., ${ }^{1}$ Hayati, M.Y., ${ }^{2}$ Khairil-Shazmin, K. and ${ }^{3}$ Zainudin, A.A. \\ ${ }^{1}$ School of Food Science and Technology, Universiti Malaysia Terengganu, 21030, Kuala Nerus, \\ Terengganu, Malaysia. \\ ${ }^{2}$ Centre for Fundamental and Liberal Education, Universiti Malaysia Terengganu, 21030, Kuala Nerus, \\ Terengganu, Malaysia. \\ ${ }^{3}$ Institute for Public Health, 40170 Shah Alam, Selangor
}

\section{Article history:}

Received: 29 September 2019

Received in revised form: 10

November 2019

Accepted: 12 November 2019

Available Online: 11

December 2019

Keywords:

Food processing,

Ultra-processed food

consumption,

Nutritional status,

Terengganu,

Malaysia

DOI:

https://doi.org/10.26656/fr.2017.4(2).320

\begin{abstract}
There is increased interest in the novel approach of classifying food based on the nature of its processing and its contribution towards diet-related diseases. Therefore, the main objective of this study is to determine the relationship between this novel food classification system and nutritional status of adults in Kuala Nerus, Terengganu. This cross-sectional study involved 200 respondents aged 18 years and above. A self- and researcher-administered questionnaire consisting of three different parts, namely a sociodemographic profile, nutritional status assessment, and food classification system (via two days 24 hours dietary recall) was used to collect data. SPSS version 20.0 was used for data analysis. Results showed that energy contributions of respondents were dominated by foods from group 1 and group 2 i.e. unprocessed food, minimally processed food and processed culinary ingredients. The energy contribution from ultra-processed food consumption was $24 \%$ of the average total daily energy consumption at $1818 \mathrm{kcal}$. The average nutritional status of respondents showed both BMI $(\mathrm{M}=25.33, \mathrm{IQR}=6.79)$ and body fat percentage $(\mathrm{M}=28.01, \mathrm{SD}=9.08)$ were overweight. Further data, including waist circumferences $(\mathrm{M}=84.57 \mathrm{~cm}, \mathrm{SD}=11.7)$; fasting blood glucose level $(\mathrm{M}=5.3$ $\mathrm{mmol} / \mathrm{L}, \mathrm{IQR}=0.80)$; total cholesterol $(\mathrm{M}=4.60 \mathrm{mmol} / \mathrm{L}, \mathrm{IQR}=1.6)$; triglycerides $(\mathrm{M}=$ $1.00 \mathrm{mmol} / \mathrm{L}, \mathrm{IQR}=0.44)$; and $\mathrm{LDL}$ level $(\mathrm{M}=2.74 \mathrm{mmol} / \mathrm{L}, \mathrm{IQR}=1.35)$ were normal. Systolic blood pressure $(\mathrm{M}=112.50 \mathrm{mmHg}, \mathrm{IQR}=20)$ and diastolic blood pressure $(\mathrm{M}=$ $78.84 \mathrm{mmHg}, \mathrm{SD}=11.73$ ) were optimal, and the HDL levels of the respondents were borderline $(\mathrm{M}=1.42 \mathrm{mmol} / \mathrm{L}, \mathrm{IQR}=0.47)$. Pearson and Spearman correlations were performed to determine the relationship between ultra-processed food consumption and nutritional status and found no significant relationship between both variables. All in all, the findings can be used in the development of evidence-based interventions aimed at encouraging the consumption of minimally processed foods and reducing ultra-processed food consumption among the general public.
\end{abstract}

\section{Introduction}

Malaysia, as a developing country, is currently experiencing epidemiologic, demographic and nutrition transitions. The rapid nutrition transition towards developed economic status has remarkably changed the dietary habits and lifestyles of the Malaysian population (National Coordinating Committee on Food and Nutrition Ministry of Health, Malaysia, 2016). These changes have had a tremendous effect on the increasing prevalence of the diet-related diseases over the past two decades, as stated in the National Plan of Action for Nutrition of Malaysia III 2016 - 2025 (Nutrition
Division, Ministry of Health Malaysia, 2016). It is believed that there is a link between the prevalence of diet-related non-communicable diseases (NCDs) and the increased consumption of ultra-processed foods, but few studies have been carried out. The Nutrition Research Priorities in Malaysia for 11th Malaysia Plan 2016-2020 has highlighted the priority to conduct studies on ultraprocessed foods and its contribution towards NCDs development.

Generally, ultra-processed food consumption is incorporated with higher energy density, higher overall fat content, higher saturated, trans-fat and higher levels 
of free sugar for their nutritional profile when compared with natural or minimally processed foods (Cediel et al., 2018). However, the role and impact of food processing in population health have been poorly studied, and no well-defined processed foods classifications have been proposed. Therefore, a recent approach for classifying food based on the extent and purpose of processing was introduced by a Brazilian researcher, and is known as the NOVA food classification (Monteiro et al., 2010). NOVA was officially recognized as a valid tool for nutrition and public health research, policy and action in 2016. NOVA classifies food into four groups: group 1 is unprocessed or minimally processed foods; group 2 is processed culinary ingredients; group 3 is processed foods; and group 4 is ultra-processed foods (Monteiro et al., 2016).

Consequently, many studies have shown that consumption of ultra-processed food has a huge negative impact on the quality of diets, bodyweight, metabolic syndrome and blood lipid profiles (Monteiro et al., 2016). However, less research has been done in Malaysia on ultra-processed food consumption. Therefore, this study is aimed to assess the relationship between ultraprocessed food consumptions (via NOVA food classification) and nutritional status among adults in a selected east coast region in Malaysia, Terengganu. Terengganu was chosen due to its high prevalence of obesity at 46.5\% (Institute for Public Health, 2015).

\section{Materials and methods}

\subsection{Research design}

This cross-sectional study was conducted in Kuala Nerus, a district in Terengganu. The sample size of this study was calculated using the Cochran formula at a $95 \%$ of confidence level, with an expected proportion of $46.5 \%$ based on the prevalence of abdominal obesity for adult ages 18 years old and above, and assuming 7\% attrition. Thus, a total of 200 respondents aged 18 to 59 years old were recruited through convenient sampling. A verbal and written informed consent form was obtained from each respondent prior to their participation. Ethical approval of this study was obtained from the University's Human Ethics Review Board of Universiti Malaysia Terengganu (UMT) with reference number: UMT/JKEPM/2017/3.

\subsection{Research instrument}

A self- and researcher-administered questionnaire consisting of three main sections were disseminated among the respondents. The first section obtained sociodemographic background information including gender, age, races, religious, marital status, educational status, occupation and monthly household income. The second part was a nutritional status assessment, including body height (via stadiometer), body weight and body fat percentage (via Tanita bioelectrical impedance), body mass index, waist circumference (via Seca measuring tape), blood pressure (via an Omron blood pressure monitor), fasting blood glucose level (via Accu Chek glucose monitor) and blood lipid profile (via Cardio Chek PA Analyzer). The third part was the food classification based on NOVA approach via a two-day 24-hours dietary recall intake. Respondents were asked to recall their food and beverages consumption for one weekday and a one weekend day. Pictures of household measurement were provided with the form for a more accurate estimation of the quantity of the foods they had consumed. Data taken from the 24-hour dietary recall was classified into NOVA food classification system and the energy provided by each food item was obtained in kcal by using Nutritionist Pro $^{\mathrm{TM}}$ software as well as few guidance books such as the Nutrient Composition of Malaysian Book and Malaysian Food atlas.

\subsection{Classification of foods according to NOVA food classification system}

NOVA classifies foods into four distinct groups. Group 1 includes unprocessed or minimally processed foods (unprocessed foods refer to edible parts of plants or animals while minimally processed foods are natural foods that undergo process such as drying, grinding, roasting, boiling, pasteurization and etc. to confiscate inedible parts). Group 2 includes processed culinary ingredients (food substances attained directly from group 1 foods for the purpose of seasoning and preparing foods from Group 1). Group 3 includes processed foods (goods somewhat simply made by placing in salt, sugar, oil, or other groups 2 elements to group 1 foods, and normally involves two or three ingredients accompanying numerous cooking methods or preservations, such as bread, cheese and non-alcoholic fermentation). Group 4 includes ultra-processed foods (referring to industrial formulations which usually made up of five or more ingredients such as salt, anti-oxidants, stabilizers, and preservatives) (Monteiro et al., 2016). Particularly important in this NOVA classification is that the underlying ingredients for each dish are classified in their respective NOVA food groups. However, due to the lack of standardized recipe provided by the respondent, it is relatively challenging to disseminate cooked dishes involving culinary ingredients into Group 1 and Group 2. Thus, we have combined Group 1 and Group 2 together, as the focus is more on processed and ultra-processed food consumption.

The average food consumption derived from the 24hour dietary recall of each NOVA group has been 
calculated and expressed as a percentage of total consumption dietary energy. The total energy of the total group is summed up as well. The average energy consumed of each group e.g. Group 1 is used as the numerator, and the denominator is the total energy of all food groups. Hence, the percentage of food consumed of the respondents from each food group can be determined from the total food consumption using the formula as follows:

Average energy obtained from Group $1=($ Energy obtained from Group 1)/(Total energy obtained from all groups) $\times 100 \%$.

\subsection{Data analysis}

All data were analyzed using Statistical Package for the Social Science (SPSS) version 20. The normality test was performed using Kolmogorov-Smirnov. Frequency, percentage, mean score (SD) or median score (IQR) were used to present descriptive data. Pearson and Spearman correlation's coefficient was applied to determine the relationship between the consumption of ultra-processed food and nutritional status of the adults in this study at $\mathrm{p}<0.05$.

\section{Results}

\subsection{Socio-demographic characteristics and nutritional status assessment of respondents}

Most of the respondents were government staff, female, Malay, had a median age of 33 years old and were married, as shown in Table 1. Most were degree holders and had a monthly household income of less than RM3000. It is apparent from Table 2 that about 53.5\% were overweight or obese, which is reflected by the median BMI of 25.33 (6.79), indicating overweight. For body fat percentage, about $44 \%$ of respondents were nutritionally at risk (i.e. overweight and obesity), which is similar to NHMS survey carried out previously in Terengganu, with $44.2 \%$ of adults having overweight or obesity (Institute for Public Health, 2015). Waist circumference is an important indicator of central obesity (NRP, 2016). Thus, from the result obtained, approximately $49 \%$ had increased or substantially increased risk of metabolic complications.

More than half of the respondents had an optimum or normal range of blood pressure level and a normal fasting blood glucose level. However, what stands out in this fasting blood glucose findings is the number of respondents being at risk of diabetes is $30.5 \%$, which was considered relatively high compared with previous NHMS report, where the percentage of known diabetes in Terengganu was $18.6 \%$ (Institute for Public Health, 2015). As for blood lipid profile, most of the respondents had either normal or optimal for their total cholesterol, low-density lipoprotein (LDL), and triglycerides levels. For high-density lipoproteins (HDL), a majority had low or borderline levels, indicating a higher risk of atherosclerosis.

Table 1. Socio-demographic characteristics of respondent $(n=200)$

\begin{tabular}{|c|c|c|}
\hline Characteristics & Number of respondents & $\begin{array}{c}\text { Percentage } \\
(\%)\end{array}$ \\
\hline \multicolumn{3}{|l|}{ Gender } \\
\hline Male & 50 & 25 \\
\hline Female & 150 & 75 \\
\hline Age (Median (IQR*)) & $33(8.19)$ years old & \\
\hline $18-25$ & 63 & 31.5 \\
\hline $26-30$ & 34 & 17 \\
\hline $31-35$ & 52 & 26 \\
\hline $36-40$ & 25 & 12.5 \\
\hline $41-45$ & 9 & 4.5 \\
\hline $46-50$ & 5 & 2.5 \\
\hline $51-55$ & 9 & 4.5 \\
\hline $56-60$ & 3 & 1.5 \\
\hline \multicolumn{3}{|l|}{ Ethnicity } \\
\hline Malay & 184 & 92 \\
\hline Chinese & 14 & 7 \\
\hline India & 1 & 0.5 \\
\hline Others & 1 & 0.5 \\
\hline \multicolumn{3}{|l|}{ Religion } \\
\hline Muslim & 185 & 92.5 \\
\hline Buddha & 13 & 6.5 \\
\hline Hindu & 1 & 0.5 \\
\hline Others & 1 & 0.5 \\
\hline \multicolumn{3}{|l|}{ Marital status } \\
\hline Single & 80 & 40 \\
\hline Married & 114 & 57 \\
\hline Divorced & 5 & 2.5 \\
\hline Widow & 1 & 0.5 \\
\hline \multicolumn{3}{|l|}{ Education Background } \\
\hline Secondary School & 44 & 22 \\
\hline Diploma & 48 & 24 \\
\hline Degree & 85 & 42.5 \\
\hline Master & 16 & 8 \\
\hline PHD & 4 & 2 \\
\hline Others & 3 & 1.5 \\
\hline \multicolumn{3}{|c|}{ Monthly Household Income } \\
\hline Less than RM 3000 & 103 & 51.5 \\
\hline RM 3000 - RM 3999 & 41 & 20.5 \\
\hline RM 4000 - RM 4999 & 24 & 12 \\
\hline RM 5000 - RM 5999 & 16 & 8 \\
\hline RM 6000 and above & 16 & 8 \\
\hline \multicolumn{3}{|l|}{ Occupation } \\
\hline Government workers & 101 & 50.5 \\
\hline Student & 60 & 30 \\
\hline Business people & 7 & 3.5 \\
\hline Private workers & 32 & 16 \\
\hline Others & 27 & 13.5 \\
\hline
\end{tabular}

Note: $* \mathrm{IQR}=$ interquartile range 
Table 2. Nutritional status of respondent $(n=200)$

\begin{tabular}{|c|c|c|}
\hline Nutritional Status & $\begin{array}{c}\text { Distribution } \\
\mathrm{n}(\%)\end{array}$ & $\begin{array}{c}\text { Mean } \pm \mathrm{SD} / \\
\text { Median }(\mathrm{IQR})\end{array}$ \\
\hline Average BMI & & $25.33(6.79) \mathrm{kgm}^{-2}$ \\
\hline Underweight $(<18.5)$ & $17(8.5)$ & \\
\hline Normal $(18.5-24.9)$ & $76(38.0)$ & \\
\hline Overweight $(25.0-29.9)$ & $68(34.0)$ & \\
\hline Obesity $(>30)$ & $39(19.5)$ & \\
\hline Body Fat Percentage $\$$ & & $28.01 \pm 9.08 \%$ \\
\hline Under Fat & $28(14.0)$ & \\
\hline Healthy & $84(42.0)$ & \\
\hline Overweight & $49(24.5)$ & \\
\hline Obesity & $39(19.5)$ & \\
\hline Waist Circumference & & $84.57 \pm 11.70 \mathrm{~cm}$ \\
\hline $\operatorname{Normal}(\mathrm{m}=<94 \mathrm{~cm}, \mathrm{w}=<80 \mathrm{~cm})$ & $102(51.0)$ & \\
\hline Increased $(\mathrm{m}=>94 \mathrm{~cm}, \mathrm{w}=>80 \mathrm{~cm})$ & $51(25.5)$ & \\
\hline Substantially Increased $(\mathrm{m}=>102 \mathrm{~cm}, \mathrm{w}=>88 \mathrm{~cm})$ & $47(23.5)$ & \\
\hline Systolic Blood Pressure & & $112.50(20) \mathrm{mmHg}$ \\
\hline Optimal $(<120 \mathrm{~mm} / \mathrm{Hg})$ & $135(67.5)$ & \\
\hline Normal $(<130 \mathrm{~mm} / \mathrm{Hg})$ & $28(14.0)$ & \\
\hline High normal (130 - 139 mm/Hg) & $22(11.0)$ & \\
\hline Hypertension Stage I (140 - 159 mm/Hg) & $13(6.5)$ & \\
\hline Hypertension Stage II $(160-179 \mathrm{~mm} / \mathrm{Hg})$ & $2(1.0)$ & \\
\hline Diastolic Blood Pressure & & $78.84 \pm 11.73 \mathrm{mmHg}$ \\
\hline Optimal $(<80$ mm/Hg) & $109(54.5)$ & \\
\hline Normal $(<85 \mathrm{~mm} / \mathrm{Hg})$ & $37(18.5)$ & \\
\hline High normal $(85-89 \mathrm{~mm} / \mathrm{Hg})$ & $18(9.0)$ & \\
\hline Hypertension Stage I (90 - 99 mm/Hg) & $27(13.5)$ & \\
\hline Hypertension Stage II $(100-109 \mathrm{~mm} / \mathrm{Hg})$ & $7(3.5)$ & \\
\hline Hypertension Stage III $(\geq 110 \mathrm{~mm} / \mathrm{Hg})$ & $2(1.0)$ & \\
\hline Fasting Blood Glucose Level & & $5.3(0.80) \mathrm{mmol} / \mathrm{L}$ \\
\hline Normal $(3.9-5.5 \mathrm{mmol} / \mathrm{L})$ & $139(69.5)$ & \\
\hline Pre-Diabetes $(5.6-7.0 \mathrm{mmol} / \mathrm{L})$ & $54(27.0)$ & \\
\hline Diabetes $(>7.0 \mathrm{mmol} / \mathrm{L})$ & $7(3.5)$ & \\
\hline Total Cholesterol & & $4.60(1.60) \mathrm{mmol} / \mathrm{L}$ \\
\hline Normal $(<5.2 \mathrm{mmol} / \mathrm{L})$ & $141(70.5)$ & \\
\hline Borderline $(5.2-6.2 \mathrm{mmol} / \mathrm{L})$ & $32(16.0)$ & \\
\hline $\operatorname{High}(>6.2 \mathrm{mmol} / \mathrm{L})$ & $27(13.5)$ & \\
\hline HDL Level & & $1.42(0.47) \mathrm{mmol} / \mathrm{L}$ \\
\hline Optimal $(>1.6 \mathrm{mmol} / \mathrm{L})$ & $53(26.5)$ & \\
\hline $\operatorname{Normal}(\mathrm{m}=>1.3 \mathrm{mmol} / \mathrm{L}, \mathrm{w}=>1.5 \mathrm{mmol} / \mathrm{L})$ & $30(15.0)$ & \\
\hline Borderline $(\mathrm{m}=1.0-1.3 \mathrm{mmol} / \mathrm{L}, \mathrm{w}=1.3-1.5 \mathrm{mmol} / \mathrm{L})$ & $58(29.0)$ & \\
\hline Low $(\mathrm{m}=<1.0 \mathrm{mmol} / \mathrm{L}, \mathrm{w}=<1.3 \mathrm{mmol} / \mathrm{L})$ & $59(29.5)$ & \\
\hline LDL Level & & $2.74(1.35) \mathrm{mmol} / \mathrm{L}$ \\
\hline Optimal $(<2.6 \mathrm{mmol} / \mathrm{L})$ & $87(43.5)$ & \\
\hline Normal $(2.6-3.3 \mathrm{mmol} / \mathrm{L})$ & $65(32.5)$ & \\
\hline Borderline $(3.4-4.1 \mathrm{mmol} / \mathrm{L})$ & $26(13.0)$ & \\
\hline $\operatorname{High}(4.1-4.9 \mathrm{mmol} / \mathrm{L})$ & $14(7.0)$ & \\
\hline Very High $(>4.9 \mathrm{mmol} / \mathrm{L})$ & $8(4.0)$ & \\
\hline Triglycerides Level & & $1.00(0.44) \mathrm{mmol} / \mathrm{L}$ \\
\hline Normal $(<1.7 \mathrm{mmol} / \mathrm{L})$ & $166(83.0)$ & \\
\hline Borderline $(1.7-2.3 \mathrm{mmol} / \mathrm{L})$ & $19(9.5)$ & \\
\hline $\operatorname{High}(2.3-5.6 \mathrm{mmol} / \mathrm{L})$ & $12(6.0)$ & \\
\hline
\end{tabular}

$\$$ Cut-off point is gender- and age- based. Source for nutritional status cut-off points: BMI (WHO, 2018), body fat (Gallagher et al., 2000), waist circumference (WHO, 2008), blood pressure (Kee et al., 2008), blood glucose (Alberti and Zimmet, 1998), total cholesterol (Jellinger et al., 2012). 
3.2 Classification of energy Intake based on NOVA food classification

Prior to underpinning energy intake into the four groups of NOVA, all under-reported and over-reported dietary intakes were eliminated via the Goldberg method, which compares energy intake (EI) against BMR. BMR was calculated based on the BMR formula by Ismail et al. (1998) in this study. Once EI:BMR was calculated, it was compared to Goldberg et al. (1991) cut-off points as follow; $\leq 0.995$ (under-reporting), $0.996-2.57$ (normal range) and $>2.58$ (over-reporting). After eliminating the under-reported $(n=33)$ and over-reported $(n=0)$ dietary intake of respondents, the energy contribution of different NOVA food groups was displayed in Table 3. From Table 3, it is apparent that the median energy intake of adults in this study was 1818.76 (480.09) kcal per day. The average energy intake from group $1+2$, group 3 and group 4 was $1393.81 \mathrm{kcal}, 8.05 \mathrm{kcal}$ and $371.77 \mathrm{kcal}$ respectively.

With respect to the main aim of this study, the most compelling finding was that the total contribution of the ultra-processed group towards overall daily energy consumption was $24 \%$. It is encouraging to compare these findings with a recent study done in Indonesia which reveals that the ultra-processed group contributed approximately 16\% (Setyowati et al., 2018). Meanwhile, a study in Brazil found that ultra-processed food consumption contributed $27.7 \%$ of overall energy intake (Moubarac et al., 2013).

\subsection{Relationship between ultra-processed food consumption and nutritional status}

Both Pearson and Spearman correlations were performed according to the normality of the respective data. It is somewhat surprising that no significant associations were found between ultra-processed food consumption and nutritional status (i.e. BMI status, body fat percentage, waist circumference, systolic blood pressure, diastolic blood pressure, total cholesterol, highdensity lipoprotein cholesterol (HDL-c), low-density lipoprotein cholesterol (LDL-c), and triglycerides) at $\mathrm{p}<$ 0.05 as shown in Table 4.

\section{Discussion}

Few were found in previous studies on the question of ultra-processed food consumption in Malaysia. Thus, this study set out with the aim of assessing the relationship between ultra-processed food consumption

Table 3. Energy Consumption from each group towards total daily energy intake (\%) in two- days 24-hour Dietary Recall (n = 167)

\begin{tabular}{lcc}
\hline \multirow{2}{*}{$\begin{array}{l}\text { Total Energy Intake by NOVA food } \\
\text { classification }(\mathrm{kcal})\end{array}$} & \multicolumn{2}{c}{ 24-HR Dietary Recall } \\
\cline { 2 - 3 } & $\begin{array}{c}\text { Percentage of contribution from each group } \\
\text { towards total daily energy intake (\%) }\end{array}$ & Mean \pm SD / Median (IQR) \\
\hline Total energy intake (kcal) & - & $1818.76(480.09)$ \\
\hline Total energy intake for: & - & $1393.81 \pm 426.38$ \\
Group 1+ Group 2 (kcal) & - & $8.05(38.10)$ \\
Group 3 (kcal) & $75 \%$ & $371.77(409.59)$ \\
Group 4 (kcal) & $1 \%$ & \\
Group 1+ Group 2 (kcal) & $24 \%$ & \\
Group 3 (kcal) & & \\
Group 4 (kcal) & & \\
\hline
\end{tabular}

Table 4. Relationship between Ultra-processed Food Consumption and Nutritional Status for two-days 24-hour Dietary Recall

\begin{tabular}{lcc}
\hline & \multicolumn{2}{c}{ Ultra-processed Food Consumption } \\
\cline { 2 - 3 } Correlation & \multicolumn{2}{c}{$(24 \mathrm{hr}$ Dietary Recall $)$} \\
\cline { 2 - 3 } & r-value & p-value \\
\hline BMI & -0.04 & 0.954 \\
Body Fat Percentage & -0.45 & 0.568 \\
Waist Circumference & 0.025 & 0.745 \\
Systolic Blood Pressure & -0.139 & 0.073 \\
Diastolic Blood Pressure & -0.046 & 0.558 \\
Fasting Blood Glucose Level & 0.038 & 0.628 \\
Total Blood Cholesterol & 0.063 & 0.42 \\
HDL Cholesterol & 0.12 & 0.121 \\
Triglycerides & 0.006 & 0.936 \\
LDL Cholesterol & 0.061 & 0.43 \\
\hline
\end{tabular}

$\mathrm{p}>0.05$ indicates no significant difference by using the Pearson and Spearmen correlation test. 
(via NOVA food classification) and nutritional status among adults in Kuala Nerus, Terengganu. The most obvious finding to emerge from the analysis is that ultraprocessed food consumption (Group 4) contributed to about one-fifth of energy intake in the daily food consumption compared to Group $1+2$ (unprocessed or minimally processed food and processed culinary ingredients) and Group 3 (processed food). Comparison of the findings with those of other studies done in higherincome countries has confirmed that the consumption of ultra-processed foods in this study is somehow still low. Higher-income countries such as US (Poti et al., 2015), UK (Moubarac et al., 2013), and Canada (Moubarac et al., 2014) had contributions of $61 \%, 63.4 \%$, and $61.7 \%$ towards total daily energy consumption, respectively. These values being greater than $60 \%$ reflects the dominance of ultra-processed foods in high-income countries' food supplies and consumption. As a middleincome country, the amount of ultra-processed food in Malaysia is considered relatively low (Juul and Hemmingsson, 2015). This study supports evidence from other middle-income countries i.e. Indonesia (Setyowati et al., 2018) and Brazil (Moubarac et al., 2013) that ultra -processed food consumption is considerably low, mostly less than $30 \%$. This can be explained by the fact that the price of ultra-processed foods in the marketplace is higher in middle-income countries when compared to higher-income countries (Moubarac et al., 2013). It is almost certain the respondents' food consumption in this study remains dominated by non-processed foods i.e. cooked foods either from home- or away-from-homeprepared, in a combination of Group 1 and Group 2. These are valuable findings, as they shed new light on the novel approach of classifying foods according to the nature of its processing, particularly in Malaysia.

Unfortunately, this study has been unable to demonstrate a significant relationship between ultraprocessed food consumption and the nutritional status of the respondents. This finding is contrary to previous studies which have suggested that ultra-processed food consumption had a significant positive association with BMI status (Louzada et al., 2015; Juul and Hemmingsson, 2015); body fat percentage (Louzada et al., 2015; Mendonca et al., 2017); waist circumference (Tavares et al., 2012); blood pressure (Tavares et al., 2012); blood glucose level (Juul and Hemmingsson, 2015; Tavares et al., 2012) and total fat (Tavares et al., 2012; Mendonça et al., 2017). In the same vein, another study done in Kenya among 453 households found no significant relationship between ultra-processed consumption and obesity (Kimenju, 2018). This discrepancy may be attributed to the small share of calories from ultra-processed foods among respondents in this study. Due to the average BMI and body fat percentage being overweight in this study, it could conceivably be hypothesized that such connections exist between both variables and the consumption of Group 1 and 2, and not because of the consumption of ultraprocessed foods. Higher consumption of total daily energy intake more than the recommended amount could be a major factor, if not the only one, causing higher BMI and body fat percentage. This provides some explanation as to why no association occurs between ultra-processed food consumption and nutritional status. However, more research on this topic needs to be undertaken before the association between consumption of ultra-processed foods and nutritional status is more clearly understood. The most important limitation lies in the fact that there is a lack of standardized recipes for typical Malaysian cuisines, which limits the classification of food groups into four different groups. Thus, further work is required to establish mechanisms underlying the NOVA approach of classifying foods mainly in Malaysia.

\section{Conclusion}

This study has provided better insights into classifying foods according to the NOVA food classification. Noteworthy, the main energy contributors were from Group 1 and 2 (unprocessed/minimally processed and culinary ingredients), followed by Group 4 (ultra-processed foods) and Group 3 (processed foods). Remarkably, the ultra-processed food consumption made up about $24 \%$ of total daily intake of adults in Kuala Nerus, Terengganu. These findings surprisingly showed that both BMI and body fat percentages were in the overweight category. Meanwhile, waist circumference, blood pressure, fasting blood glucose, total cholesterol, LDL, and triglycerides were in a normal range. In general, therefore, it seems that the biochemical assessment of the nutritional status indicates a healthy level; but not for the anthropometry assessments which reflect the respondents were nutritionally at risk. Unfortunately, no significant relationship was found between ultra-processed food consumption and BMI status, body fat percentage, waist circumferences, blood pressure, fasting blood glucose level and blood lipid profile in this study. All in all, these findings have significant implications for the understanding of how ultra-processed food consumption contributes towards total energy intake among the respondents, as the evidence of ultra-processed food consumption has been purely anecdotal in Malaysia.

\section{Conflict of Interest}

The authors declare no conflict of interest. 


\section{Acknowledgements}

The authors thank all the respondents for their participation, full cooperation, and patience in completing the study. This study is funded under the Universiti Malaysia Terengganu (UMT)'s Young Researcher scheme (Vot No.: 68007/2016/83).

\section{References}

Alberti, K.G.M.M. and Zimmet, P.F. (1998). Definition, diagnosis and classification of diabetes mellitus and its complications. Part 1: diagnosis and classification of diabetes mellitus. Provisional report of a WHO consultation. Diabetic Medicine, 15(7), 539-553. https://doi.org/10.1002/(SICI)1096-9136(199807)

15:7<539::AID-DIA668>3.0.CO;2-S

Cediel, G., Reyes. M., da Costa Louzada, M.L., Steele, E.M., Monteiro, C.A., Corvalán, C. and Uauy, R. (2018). Ultra-processed foods and added sugars in the Chilean diet. Public Health Nutrition, 21(1), 125133. https://doi.org/10.1017/S1368980017001161

Gallagher, D., Heymsfield, S.B., Heo, M., Jebb, S.A., Murgatroyd, P.R. and Sakamoto, Y. (2000). Healthy percentage body fat ranges: an approach for developing guidelines based on body mass indexThe American Journal of Clinical Nutrition, 72(3), 694-701. https://doi.org/10.1093/ajen/72.3.694

Goldberg, G.R., Black, A.E., Jebb, S.A., Cole, T.J., Murgatroyd, P.R., Coward, W.A. and Prentice, A.M. (1991). Critical evaluation of energy intake data using fundamental principles of energy physiology: 1. Derivation of cut-off limits to identify underrecording. European Journal of Clinical Nutrition, 45(12), 569-581.

Institute for Public Health (IPH). (2015). National Health and Morbidity Survey 2015 (NHMS 2015). NonCommunicable Diseases, Risk Factors and Other Health Problems. Vol. 2. Retrieved on March 18, 2018 from MOH Website: http://iku.moh.gov.my/ images/IKU/Document/REPORT/

nhmsreport2015vol2.pdf

Jellinger, P.S., Smith, D.A., Mehta, A.E., Ganda, O., Handelsman, Y., Rodbard, H.W., Shepherd, M.D. and Seibel, J.A. (2012). AACE task force for the management of dyslipidemia and prevention of atherosclerosis writing committee. Endocrine Practice, 18(2), 270-293. https://doi.org/10.4158/ EP.18.2.269

Juul, F. and Hemmingsson, E. (2015). Trends in consumption of ultra-processed foods and obesity in Sweden between 1960 and 2010. Public Health Nutrition, 18(17), 3096-3107. https:// doi.org/10.1017/S1368980015000506
Kee, C.C., Jamaiyah, H., Noor Safiza, M.N., Khor, G.L., Suzana, S., Jamalludin, A.R., Rahmah, R., Ahmad, A.Z., Ruzita, A.T., Wong, N.F. and Ahmad Fauzi, Y. (2008). Abdominal Obesity in Malaysian Adults: National Health and Morbidity Survey III (NHMS III, 2006). Malaysian Journal of Nutrition, 14(2), 125-135.

Kimenju, S.C. (2018). Ultra-Processed foods and Obesity in Central Kaya. In Barling, D. and Fanzo, J. (Eds.). Advances in Food Security and Sustainability. Vol. 3, p. 69-92. USA: Elsevier. https://doi.org/10.1016/bs.af2s.2018.09.003

Louzada, M.L.D.C., Martins, A.P.B., Canella, D.S., Baraldi, L.G., Levy, R.B., Claro, R.M., Moubarac, J. -C., Cannon, G. and Monteiro, C.A. (2015). Ultraprocessed foods and the nutritional dietary profile in Brazil. Revista de Saude Publica, 49. https:// doi.org/10.1590/S0034-8910.2015049006132

Mendonça, R.D.D., Lopes, A.C.S., Pimenta, A.M., Gea, A., Martinez-Gonzalez, M.A. and Bes-Rastrollo, M., (2017). Ultra-processed food consumption and the incidence of hypertension in a Mediterranean cohort: The Seguimiento Universidad de Navarra Project. American Journal of Hypertension, 30(4), 358-366. https://doi.org/10.1093/ajh/hpw137

Monteiro, C.A., Cannon, G., Levy, R., Moubarac, J.C., Jaime, P., Martins, A.P., Canella, D., Louzada, M. and Parra, D. (2016). NOVA. The star shines bright. World Nutrition, 7(1-3), 28-38.

Monteiro, C.A., Levy, R.B., Claro, R.M., Castro, I.R.R.D. and Cannon, G. (2010). A new classification of foods based on the extent and purpose of their processing. Cadernos de Saude Publica, 26(11), 2039-2049. https://doi.org/10.1590/ S0102-311X2010001100005

Moubarac, J.C., Batal, M., Martins, A.P.B., Claro, R., Levy, R.B., Cannon, G. and Monteiro, C. (2014). Processed and ultra-processed food products: consumption trends in Canada from 1938 to 2011. Canadian Journal of Dietetic Practice and Research, 75(1), 15-21. https://doi.org/10.3148/75.1.2014.15

Moubarac, J.C., Claro, R.M., Baraldi, L.G., Levy, R.B., Martins, A.P.B., Cannon, G. and Monteiro, C.A. (2013). International differences in cost and consumption of ready-to-consume food and drink products: United Kingdom and Brazil, 2008-2009. Global Public Health, 8(7), 845-856. https:// doi.org/10.1080/17441692.2013.796401

Nutrition Division, Ministry of Health Malaysia. (2016). National Plan of Action for Nutrition of Malaysia III 2016-2025. Malaysia: National Coordinating Committee on Food and Nutrition (NCCFN). Retrieved on February 18, 2018 from MOH Website: 
http://nutrition.moh.gov.my/wp-content/

uploads/2016/12/NPANM_III.pdf

National Coordinating Committee on Food and Nutrition Ministry of Health, Malaysia. (2016). Nutrition Research Priorities in Malaysia for 11th Malaysian Plan (2016-2020). Malaysia: Technical Working Group on Nutrition Research, National Coordinating Committee on Food and Nutrition (NCCFN), Ministry of Health.

Poti, J.M., Mendez, M.A., Ng, S.W. and Popkin, B.M. (2015). Is the degree of food processing and convenience linked with the nutritional quality of foods purchased by US households? The American Journal of Clinical Nutrition, 101(6), 1251-1262. https://doi.org/10.3945/ajcn.114.100925

Setyowati, D., Andarwulan, N. and Giriwono, P.E. (2018). Processed and ultraprocessed food consumption pattern in the Jakarta Individual Food Consumption Survey 2014. Asia Pacific Journal of Clinical Nutrition, 27(4), 840-847.

Tavares, L.F., Fonseca, S.C., Rosa, M.L.G. and Yokoo, E.M. (2012). Relationship between ultra-processed foods and metabolic syndrome in adolescents from a Brazilian Family Doctor Program. Public Health Nutrition, 15(1), 82-87. https://doi.org/10.1017/ S1368980011001571

WHO (World Health Organization). (2018). Waist Circumference and Waist-Hip Ratio: report of a WHO expert consultation, Geneva, 8-11 December 2008. Retrieved on March 26, 2018 from Website: http://apps.who.int/iris/

bitstream/10665/44583/1/9789241501491_eng.pdf?u

WHO (World Health Organization). (2018). Global Database on Body Mass Index. An Interactive Surveillance Tool for Monitoring Nutrition Transition. Retrieved on March 24, 2018 from WHO Website: http://www.who.int/bmi/index 